Research Article

\title{
Evaluation of Fracture Resistance of Asphalt Mixtures Using the Single-Edge Notched Beams
}

\author{
Biao Ding $\mathbb{D}^{1},{ }^{1}$ Xiaolong Zou $\mathbb{D}^{2,3,4}{ }^{2}$ Zixin Peng, ${ }^{1}$ and Xiang Liu ${ }^{5}$ \\ ${ }^{1}$ CCCC First Highway Consultants Co., Ltd., Xi'an, Shaanxi 710065, China \\ ${ }^{2}$ School of Architecture and Civil Engineering, Xi'an University of Science and Technology, Xi'an, Shaanxi, China \\ ${ }^{3}$ Guangxi Key Lab of Road Structure and Materials, Guangxi Transportation Research \& Consulting Co., Ltd., \\ Nanning, Guangxi, China \\ ${ }^{4}$ Key Laboratory for Special Area Highway Engineering of Ministry of Education, Chang'an University, Xi'an, Shaanxi, China \\ ${ }^{5}$ School of Highway, Chang'an University, Xi'an, Shaanxi, China
}

Correspondence should be addressed to Xiaolong Zou; zouxiaolong_1234@163.com

Received 25 October 2017; Accepted 20 March 2018; Published 12 April 2018

Academic Editor: Hiroshi Noguchi

Copyright (c) 2018 Biao Ding et al. This is an open access article distributed under the Creative Commons Attribution License, which permits unrestricted use, distribution, and reproduction in any medium, provided the original work is properly cited.

To determine and compare the fracture properties of different asphalt mixtures, single-edge notched beam (SENB) tests using three types of asphalt mixtures were applied in this study under the conditions of different notched depths and different temperatures. The effects of notched depths and temperatures on the fracture toughness and fracture energy were analyzed. The results indicate that the notch depth has no significant effects on the fracture toughness and the fracture energy, but the gradation has relatively obvious effects on the fracture energy, which the larger contents of course aggregate leads to increase the discreteness of the fracture energy of the specimen. The temperature has significant effects on the ultimate loads, fracture energy, and fracture toughness. The ultimate loads of the SENBs reach the peak value at $0^{\circ} \mathrm{C}$, which could be resulted in that viscoelastic properties of asphalt mixture depend with temperatures. The fracture toughness at $-20^{\circ} \mathrm{C}$ of continuously graded asphalt mixtures are higher than those of gap-graded asphalt mixtures. On the contrary, the fracture toughness of gap-graded asphalt mixtures is higher at temperatures from $-10^{\circ} \mathrm{C}$ to $20^{\circ} \mathrm{C}$. The fracture energy increases with temperatures, and the fracture energy of SMA-13 is significantly larger than those of AC-13 and AC-16.

\section{Introduction}

The research on the fracture characteristics of asphalt mixture is one of important topics on the properties of asphalt mixture. The main research methods for analysis and evaluation of the fracture characteristics include the numerical simulation method and fracture test method [1-3].

The numerical simulation is usually realized by the finite element method (FEM) and discrete element method (DEM). Two-dimensional (2D) micromechanical models using FEM and DEM have been developed to simulate microscale crack propagation of cemented particulate materials, which obtained well explanations of observed crack failures of the samples $[1,2,4,5]$. The results of FEM simulation and the results of DEM simulation are usually compared to evaluate the similarities and differences. The findings show that the results of FEM simulation and DEM simulation have a fundamental similarity and, at the same time, have some basic differences [4]. Furthermore, threedimensional (3D) model development has become a trend for the numerical simulation of fracture analysis.

The fracture test has three typical test methods, namely, the single-edge notched beam (SENB) test, the semicircular bending (SCB) test, and the disk-shaped compact tension $(\mathrm{DC}(\mathrm{T}))$ test, which are mainly applied to obtain the fracture characteristics of asphalt concrete [6-9]. These three methods have different specimen geometries, application occasions, and fracture models, so the results can hardly be compared directly $[8,10]$. 


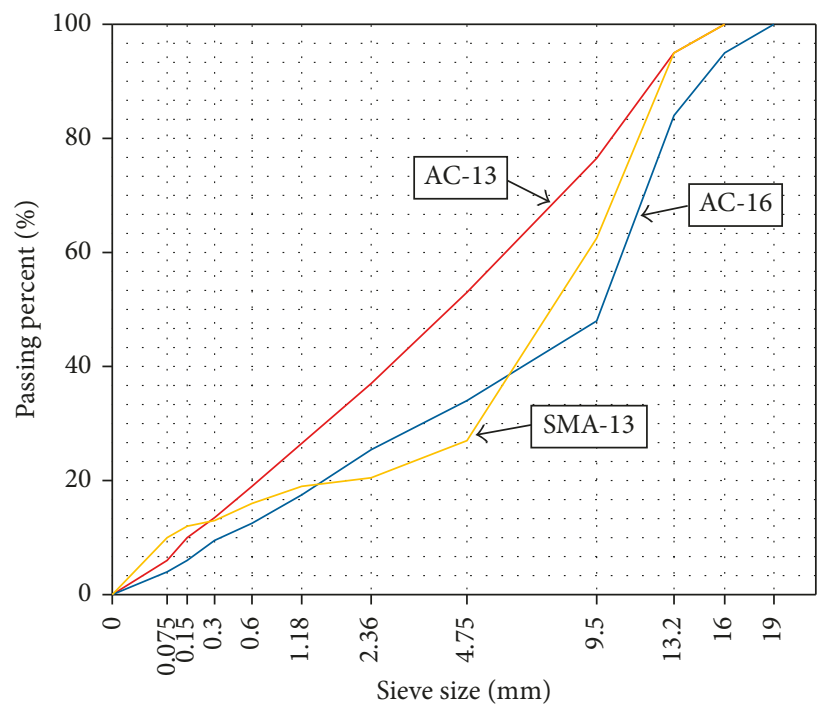

FIgURE 1: Experimental gradation curves for 0.45 power gradation graph.

TABle 1: Properties of base asphalt.

\begin{tabular}{llcrr}
\hline Test item & Unit & Test result & Test method \\
\hline Penetration $\left(25^{\circ} \mathrm{C}, 5 \mathrm{~s}, 100 \mathrm{~g}\right)$ & & $0.1 \mathrm{~mm}$ & 87.9 & $\mathrm{~T} 0604-2011$ \\
Ductility $\left(5^{\circ} \mathrm{C}, 5 \mathrm{~cm} / \mathrm{min}\right)$ & $\mathrm{cm}$ & $>150$ & $\mathrm{~T} 0605-2011$ \\
Softening point $(\mathrm{R} \& \mathrm{~B})$ & ${ }^{\circ} \mathrm{C}$ & 48.8 & $\mathrm{~T} 0606-2011$ \\
& & $\%$ & 0.15 & $\mathrm{~T} 0610-2011$ \\
Residue after TFOT & Quality change & $\%$ & 69.0 & $\mathrm{~T} 0609-2011$ \\
& Penetration ratio $\left(25^{\circ} \mathrm{C}\right)$ & $\mathrm{cm}$ & 34.8 & $\mathrm{~T} 0604-2011$ \\
& Ductility $\left(15^{\circ} \mathrm{C}\right)$ & & $\mathrm{T} 0605-2011$ \\
\hline
\end{tabular}

For asphalt mixtures, one kind of viscoelastic materials, the fracture characteristics are not only related to the initial crack depth but also to the temperature. Therefore, the aim of this study was to determine and compare the fracture properties of three typical surface layer asphalt mixtures, namely, two kinds of two continuously graded asphalt mixtures and a stone mastic asphalt (SMA), at different conditions of the initial crack depth and the temperature. Considering as the simple and widely used model, the SENB test was applied in this study and the SENB with different notched depths were tested at different temperatures.

\section{Materials and Methods}

2.1. Materials. Three asphalt mixtures used in this study included two continuously graded asphalt mixtures with nominal maximum aggregate size (NMAS) of $13.2 \mathrm{~mm}$ and $16 \mathrm{~mm}$ (AC-13 and AC-16) and a gap-graded stone mastic asphalt with NMAS of $13.2 \mathrm{~mm}$ (SMA-13). The experimental gradation curves of those three asphalt mixtures are shown in Figure 1. A base asphalt SK90 was used in AC-13 and AC16 , and a styrene-butadiene-styrene- (SBS-) modified asphalt binder produced by Shanxi Guolin Huatai Asphaltic Products Co., Ltd. was used in SMA-13. The properties of the base asphalt and the SBS-modified asphalt binder are shown in Tables 1 and 2, respectively.
The coarse aggregate and fine aggregate used in those three mixtures are basalt, and the properties are listed in Tables 3 and 4 . The mineral filler used in this study is limestone powder, and the properties are listed in Table 5. Besides, lignin fibers were used as the stabilizer in SMA mixture. Table 6 lists the properties of fibers. Design asphalt contents were $5.0 \%$ for AC-13, 4.6\% for AC-16, and $6.0 \%$ for SMA-13, which had $3.9 \%, 4.3 \%$, and $4.1 \%$ void content, respectively. In addition, $0.3 \%$ of fiber was used in SMA-13.

2.2. Fabrication of Single-Edge Notched Beam. The slab specimens $(300 \mathrm{~mm} \times 300 \mathrm{~mm} \times 50 \mathrm{~mm})$ were fabricated using a rolling wheel compactor. The slab specimens were sawed into beams with the diameters of $250 \mathrm{~mm}$ (length) $\times$ $35 \mathrm{~mm}$ (height) $\times 30 \mathrm{~mm}$ (width).

A notch of designed depth, approximately $4 \mathrm{~mm}$ wide, with a square end, was sawed at the middle point of each beam, and single-edge notched beams (SENB) were obtained. A group of single-edge notched beams are shown in Figure 2.

2.3. Three-Point Bending Tests. Different notch depths and different test temperatures were considered in this study. The SENB with notch depth of $0 \mathrm{~mm}$ (without initial notch), $4 \mathrm{~mm}, 8 \mathrm{~mm}, 12 \mathrm{~mm}$, and $16 \mathrm{~mm}$ was applied for three-point 
TABLe 2: Properties of SBS-modified asphalt.

\begin{tabular}{|c|c|c|c|c|}
\hline Test item & & Unit & Test result & Test method \\
\hline Penetration $\left(25^{\circ} \mathrm{C}, 5 \mathrm{~s}, 100 \mathrm{~g}\right)$ & & $0.1 \mathrm{~mm}$ & 66.5 & T0604-2011 \\
\hline Ductility $\left(5^{\circ} \mathrm{C}, 5 \mathrm{~cm} / \mathrm{min}\right)$ & & $\mathrm{cm}$ & 38 & T0605-2011 \\
\hline Softening point $(R \& B)$ & & ${ }^{\circ} \mathrm{C}$ & 77.4 & T0606-2011 \\
\hline Kinematic viscosity $\left(135^{\circ} \mathrm{C}\right)$ & & $\mathrm{Pa} \cdot \mathrm{s}$ & 2.0 & T0625-2011 \\
\hline Flash point & & ${ }^{\circ} \mathrm{C}$ & 263 & T0611-2011 \\
\hline Solubility & & $\%$ & 99.58 & T0607-2011 \\
\hline Elastic recovery $\left(25^{\circ} \mathrm{C}\right)$ & & $\%$ & 97 & T0662-2000 \\
\hline \multirow{3}{*}{ Residue after TFOT } & Quality change & $\%$ & 0.09 & $\begin{array}{l}\text { T0610-2011 } \\
\text { T0609-2011 }\end{array}$ \\
\hline & Penetration ratio $\left(25^{\circ} \mathrm{C}\right)$ & $\%$ & 73 & T0604-2011 \\
\hline & Ductility $\left(5^{\circ} \mathrm{C}\right)$ & $\mathrm{cm}$ & 23 & T0605-2011 \\
\hline
\end{tabular}

TABle 3: Properties of coarse aggregate.

\begin{tabular}{lccc}
\hline Test item & Unit & Test result & Test method \\
\hline Apparent relative density & $/$ & 2.953 & T0304 \\
Bulk density & $/$ & 2.886 & T0304 \\
Acicular content & $\%$ & 3.95 & T0312 \\
Particle content of less than $0.075 \mathrm{~mm}$ & $\%$ & 0.2 & T0310 \\
Soft stone content & $\%$ & 1.0 & $\mathrm{~T} 0320$ \\
Crushing value & $\%$ & 12.9 & $\mathrm{~T} 0316$ \\
Crushing value $\left(200^{\circ} \mathrm{C}\right.$ for 5 hours $)$ & $\%$ & 13.6 & $\mathrm{~T} 0316$ \\
Firmness & $\%$ & 2.0 & $\mathrm{~T} 0314$ \\
Water absorption rate & $\%$ & 0.78 & $\mathrm{~T} 0314$ \\
Los Angeles wear value loss & $\%$ & 13.7 & $\mathrm{~T} 0317$ \\
Los Angeles wear value loss $\left(200^{\circ} \mathrm{C}\right.$ for 5 hours) & $\%$ & 14.4 & T0317 \\
Polished value & PSV & 44 & T0321 \\
Adhesion & Grade & 5 & T0305 \\
\hline
\end{tabular}

TABle 4: Properties of fine aggregate.

\begin{tabular}{lccc}
\hline Test item & Unit & $\begin{array}{c}\text { Test } \\
\text { result }\end{array}$ & $\begin{array}{c}\text { Test } \\
\text { method }\end{array}$ \\
\hline Apparent relative density & $/$ & 2.726 & T0329 \\
Bulk density & $/$ & 2.696 & T0329 \\
Sturdiness $(>0.3 \mathrm{~mm})$ & $\%$ & 4 & T0340 \\
Particle content of less than $0.075 \mathrm{~mm}$ & $\%$ & 9.9 & T0340 \\
Sand equivalent & $\%$ & 82 & T0334 \\
Methylene blue value & $\mathrm{g} / \mathrm{kg}$ & 1.5 & T0349 \\
Angularity & $\mathrm{s}$ & 38.6 & T0345 \\
\hline
\end{tabular}

Table 5: Properties of mineral filler.

\begin{tabular}{lcc}
\hline Property & Unit & Result \\
\hline Apparent specific gravity & - & 2.693 \\
Water content & $\%$ & 0.34 \\
Hydrophilic coefficient & - & 0.58 \\
Plasticity index & $\%$ & 2.5 \\
\hline
\end{tabular}

TABle 6: Properties of lignin fibers.

\begin{tabular}{lcc}
\hline Property & Unit & Result \\
\hline Length & $\mathrm{mm}$ & $<6$ \\
Ash content & $\%$ & 19.64 \\
pH & - & 7.6 \\
Hygroscopicity & $\%$ & 6.57 \\
Water content (by weight) & $\%$ & 0.85 \\
\hline
\end{tabular}

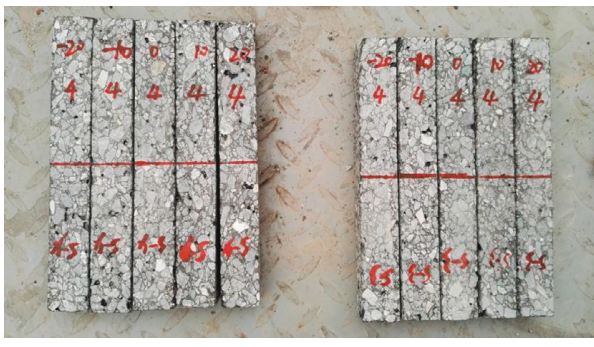

Figure 2: Single-edge notch beams.

bending tests at $-10^{\circ} \mathrm{C}$. The SENB with notch depth of $4 \mathrm{~mm}$ was applied for three-point bending tests at $-20^{\circ} \mathrm{C},-10^{\circ} \mathrm{C}$, $0^{\circ} \mathrm{C}, 10^{\circ} \mathrm{C}$, and $20^{\circ} \mathrm{C}$.

A material test system (MTS-810) with an environmental chamber was used to perform the three-point bending tests. The configuration of the three-point bending test on a SENB is shown in Figure 3. The loading span is $200 \mathrm{~mm}$. In a three-point bending test, the load using a constant displacement rate of $0.05 \mathrm{~mm} / \mathrm{min}$ was directly applied at the point right above the notch on the upper surface. The midspan displacement $\delta$ was recorded at a sampling frequency of $10 \mathrm{~Hz}$ during the whole loading process until failure. The load-displacement curve can be drawn to obtain the peak loads. 


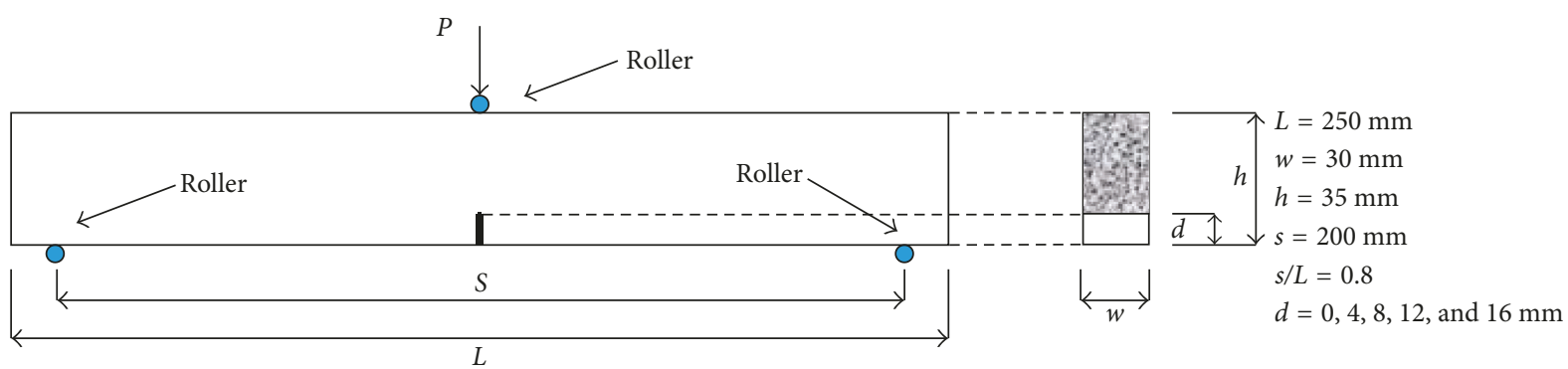

Figure 3: A schematic illustration of the three-point bending test on a single-edge notched beam.

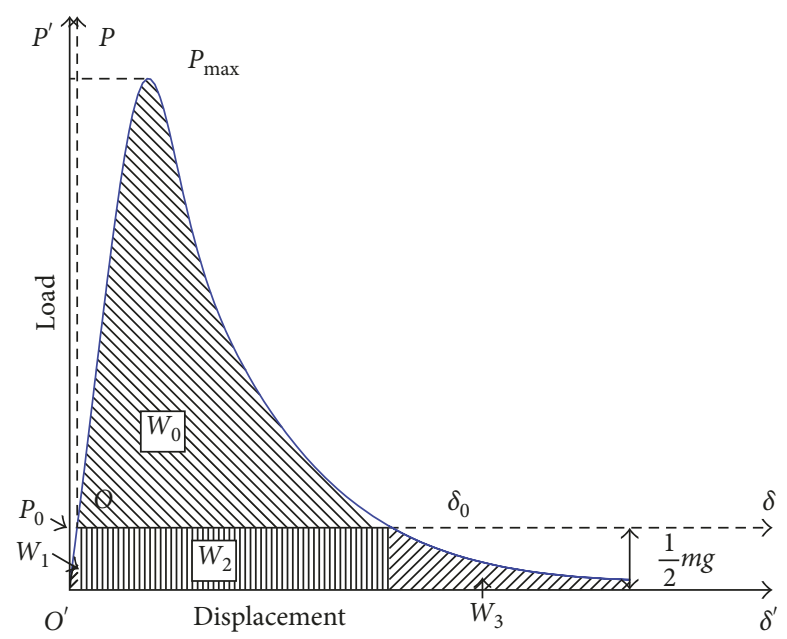

Figure 4: A load-displacement curve for a stable three-point bend test on a single-edge notched beam. $W_{0}$ defines the area under the loaddisplacement curve if there is no compensation for the energy supplied by the weight of the beam, $m$ is the weight of the beam (between the supports), and $g=9.81 \mathrm{~m} / \mathrm{s}^{2}[17]$.

\section{Theoretical Background}

3.1. Fracture Toughness. The SENB specimen loaded in a three-point bending configuration and notched at the midpoint, as shown in Figure 3, is under the mode of tension, so the fracture toughness for a SENB specimen is given as follows $[11,12]$ :

$$
K_{\mathrm{I}}=\sigma_{0} Y_{\mathrm{I}} \sqrt{\pi a}
$$

where $a$ is the notch depth, $\sigma_{0}$ is the applied stress, and $Y_{\mathrm{I}}$ is the normalized fracture toughness. The applied stress is given as follows:

$$
\sigma_{0}=\frac{3 P s}{2 h^{2} w}
$$

where $P$ is the applied load, $s$ is the loading span, and $h$ and $w$ are the specimen height and width, respectively, as seen in Figure 3. The normalized fracture toughness, $Y_{\mathrm{I}}$, is given by the following analytical expression [3, 13-15]:

$$
Y_{\mathrm{I}}=\frac{1.99-(a / W)(1-(a / W))\left(2.15-(3.93 a / W)+\left(2.7 a^{2} / W^{2}\right)\right)}{\sqrt{\pi}(1+(2 a / W))(1-(a / W))^{3 / 2}} .
$$

3.2. Fracture Energy. Fracture energy, $G_{F}$, is defined as the area under the load-displacement curve divided by the ligament area, which could be expressed as follows [16]:

$$
G_{\mathrm{F}}=\frac{W}{A_{\text {lig }}}
$$

where $W$ is the work of fracture for an entire crack propagation period and $A_{\text {lig }}$ is the area of the ligament.
Figure 4 shows the work of fracture $W$ for crack propagation, which can be expressed as (5), considering the effects of the self-weight of the beam $[17,18]$.

$$
W=W_{0}+W_{1}+W_{2}+W_{3},
$$

where $W_{0}$ is the work performed by the external force $P$ for crack propagation and $W_{1}, W_{2}$, and $W_{3}$ are the additional works caused by the self-weight of the beam. Based on special 


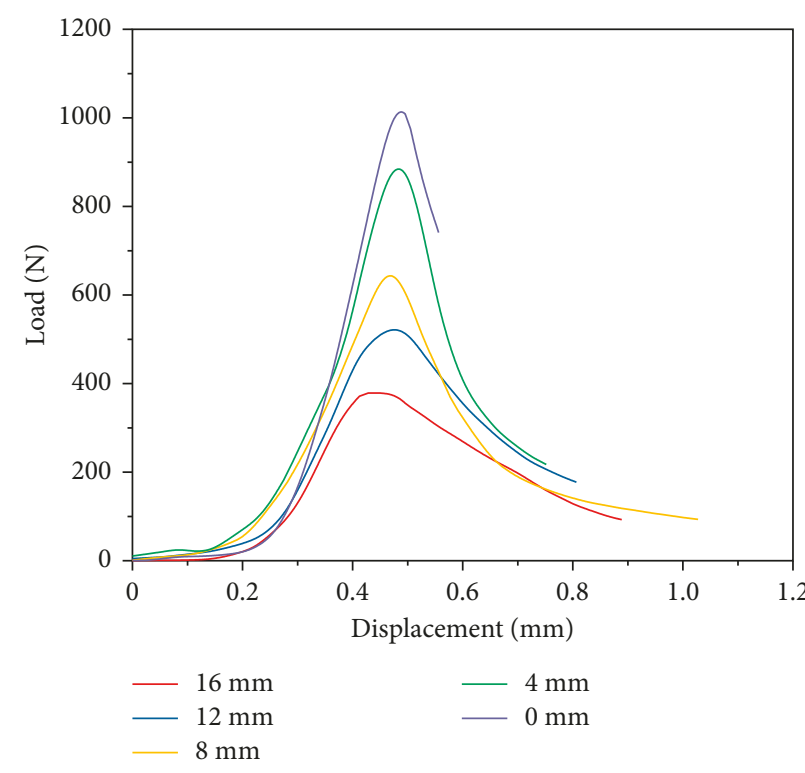

(a)

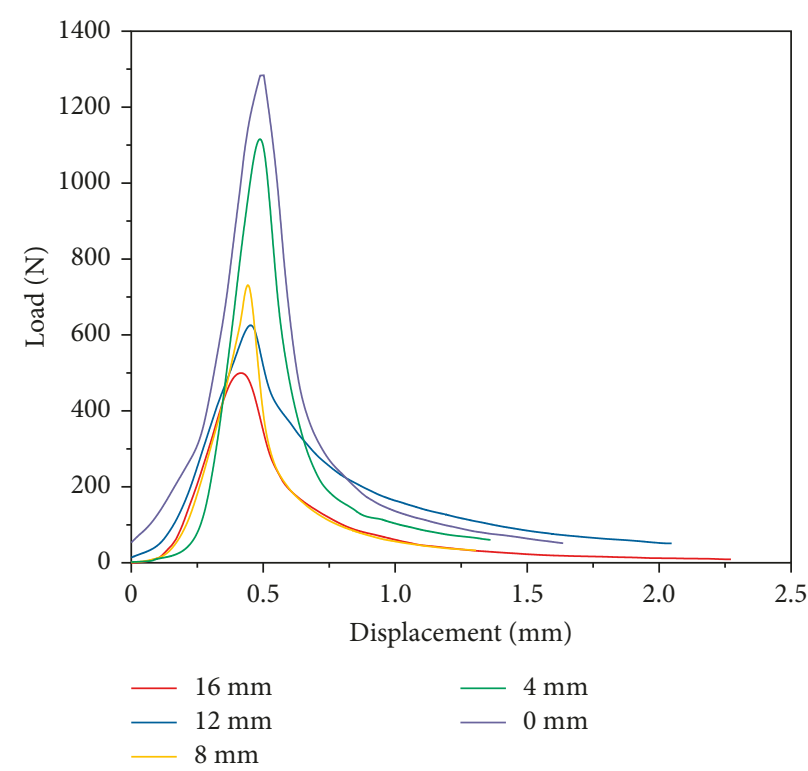

(b)

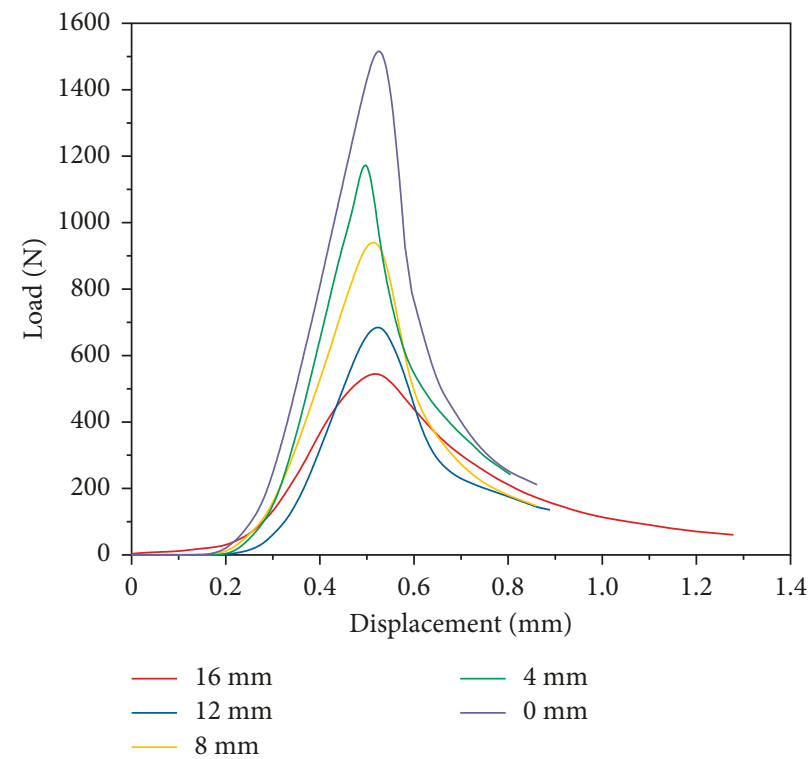

(c)

Figure 5: Load-displacement curves for different notch depths: (a) AC-13, (b) AC-16, and (c) SMA-13.

hypothetic situation, $W_{2}$ and $W_{3}$ can be calculated as follows $[12,17]:$

$$
W_{2}=W_{3}=\frac{1}{2} m g \delta_{0} .
$$

According to (4)-(6), fracture energy, $G_{\mathrm{F}}$, can be expressed as (7) [16], so that the fracture energy of asphalt mixture could be calculated from a load-displacement curve recorded [19].

$$
G_{\mathrm{F}}=\frac{W}{A_{\text {lig }}}=\frac{\left[\int_{0}^{\delta_{0}} p(\delta) d \delta+m g \delta_{0}\right]}{A_{\text {lig }}},
$$

where $G_{\mathrm{F}}=$ the fracture energy $(\mathrm{N} / \mathrm{m}), m=m_{1}+m_{2}(\mathrm{~kg})$, $m_{1}=M s / L$ (weight of the beam between the supports),
$M=$ weight of the specimen, $m_{2}=$ weight of the part of the loading arrangement which is not attached to the machine but follows the beam until failure, $\delta_{0}=$ the midspan displacement of the specimen at failure $(\mathrm{m}), \delta=$ midspan displacement $(\mathrm{m}), g=9.81\left(\mathrm{~m} / \mathrm{s}^{2}\right)$, and $A_{\text {lig }}=$ area of the ligament. $P, s$, and $L$ are shown in Figure 3 .

\section{Results and Discussions}

\subsection{Effects of Notch Depth}

4.1.1. Displacement. The load-displacement curves were recorded by three-point bending tests. Figure 5 are shown the load-displacement curves of the three mixtures of SENB specimens with different notch depths. According to Figure 5, 


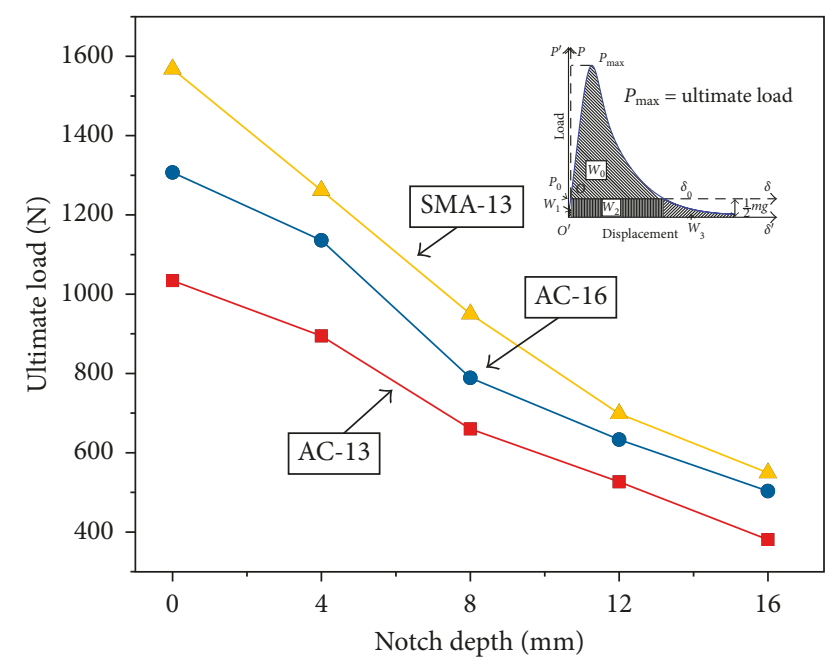

FIgURE 6: Ultimate loads for different notch depths.

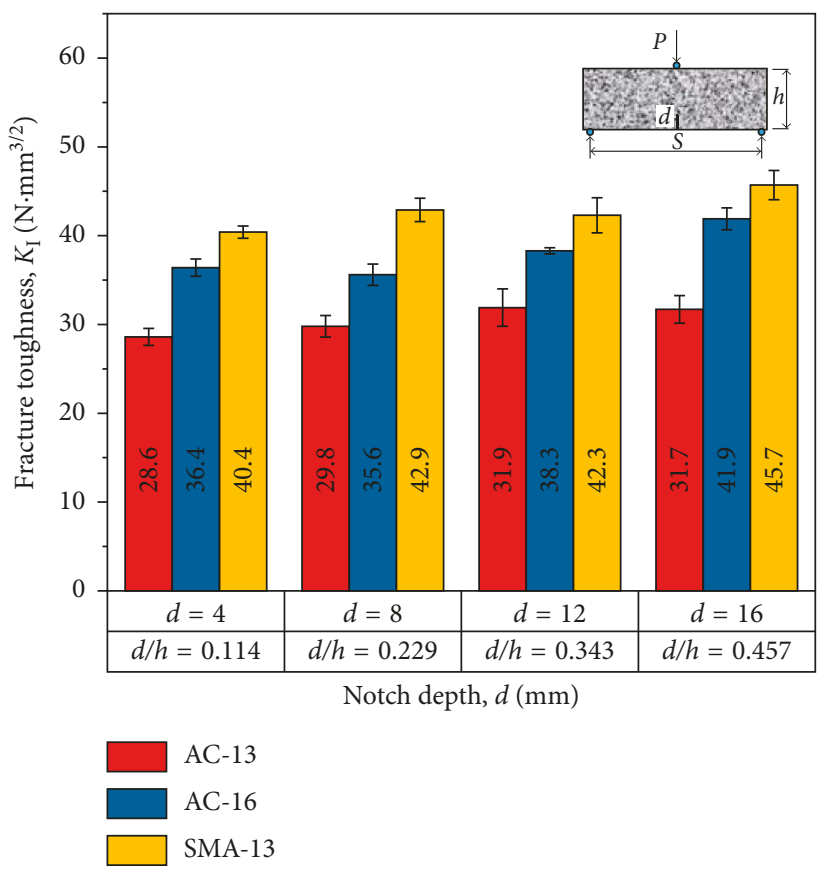

FiguRe 7: Fracture toughness for different notch depths.

the load-displacement curves of the mixtures present typical three stages. At the first stage, the load increases linearly with the displacement up to the peak. At the second stage, after the peak, the load decreases largely with the displacement and, at the same time, the fracture develops rapidly. At the third stage, the load decreases steadily until the specimen fracture failure.

4.1.2. Ultimate Load. The ultimate loads of the three-point bending tests can be obtained through the load-displacement curves. Figure 6 shows the ultimate loads for the SENB specimens of the three mixtures with different notch depths at $10^{\circ} \mathrm{C}$. From Figure 6 , with the increase of notch depth, the ultimate loads of three kinds of asphalt mixture show a linear downward trend. In addition, under the same conditions of

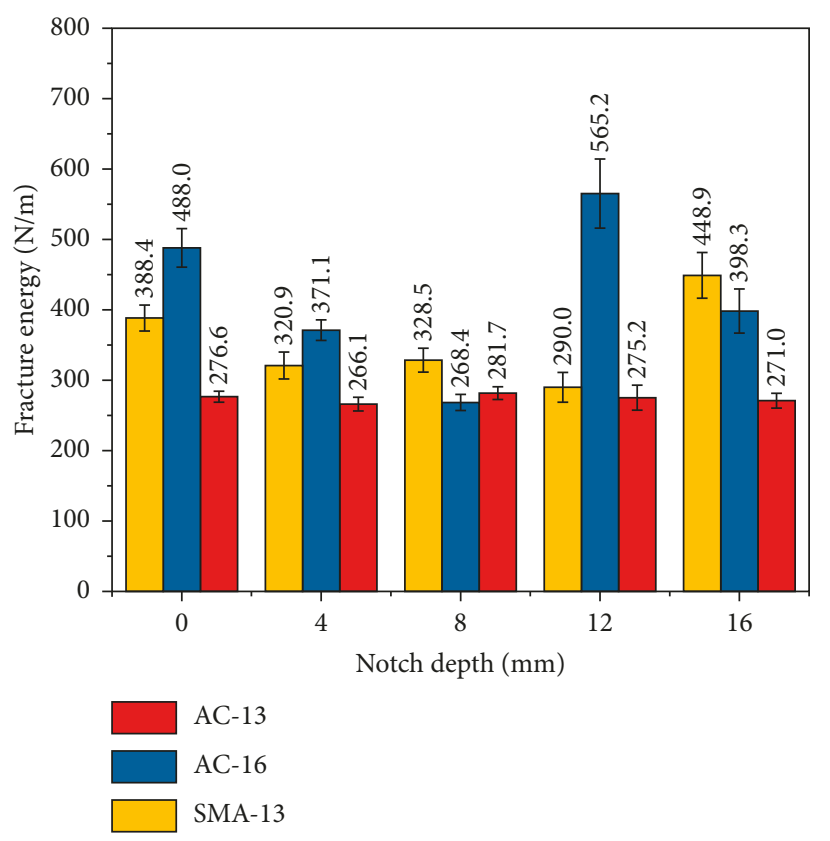

FIGURE 8: Fracture energy for different notch depths.

notch depth, the ultimate load of the AC-13 specimen is minimum, AC-16 is moderate, and SMA-13 is maximum among the three asphalt mixtures. It is analyzed that the higher ultimate load of the SMA-13 specimen is attributed to the material composition, which the utilization of the SBSmodified asphalt and the fiber can contribute to improving the tensile strength and the ultimate load.

4.1.3. Fracture Toughness. Fracture toughness, $K_{\mathrm{I}}$, for SENB specimens with different notch depths can be determined by (1)-(3). The calculations of fracture toughness for different notch depths are shown in Figure 7 . With the increase of notch depth, for the three asphalt mixtures, the fracture toughness increases moderately. It is notable that the fracture toughness for SMA-13 is largest among the three asphalt mixtures at the same conditions of notch depth.

4.1.4. Fracture Energy. From load-displacement curves, the fracture energy of mixtures was calculated by using (7). Fracture energy of the three-point bending test on SENB specimens with different notch depths is shown in Figure 8. From Figure 8, it can be seen that the notch depth has no significant effects on the fracture energy of AC-13 specimens. For AC-16 and SMA-13, there is no obvious regularity of the notch depth versus the fracture energy. The contents of fine aggregate (less than $2.36 \mathrm{~mm}$ ) of AC-16 and SMA-13 are relatively small, and the contents of course aggregate are relatively large, which results in increasing the discreteness of the fracture energy of the specimen.

\subsection{Effects of Temperature}

4.2.1. Displacement. The load-displacement curves were recorded by three-point bending tests. Figure 9 shows the 


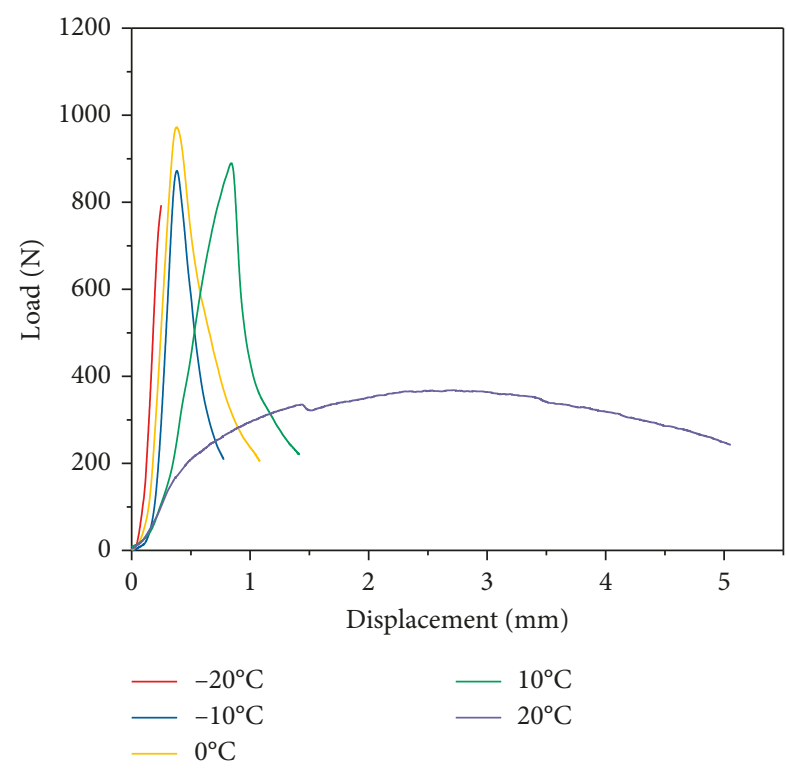

(a)

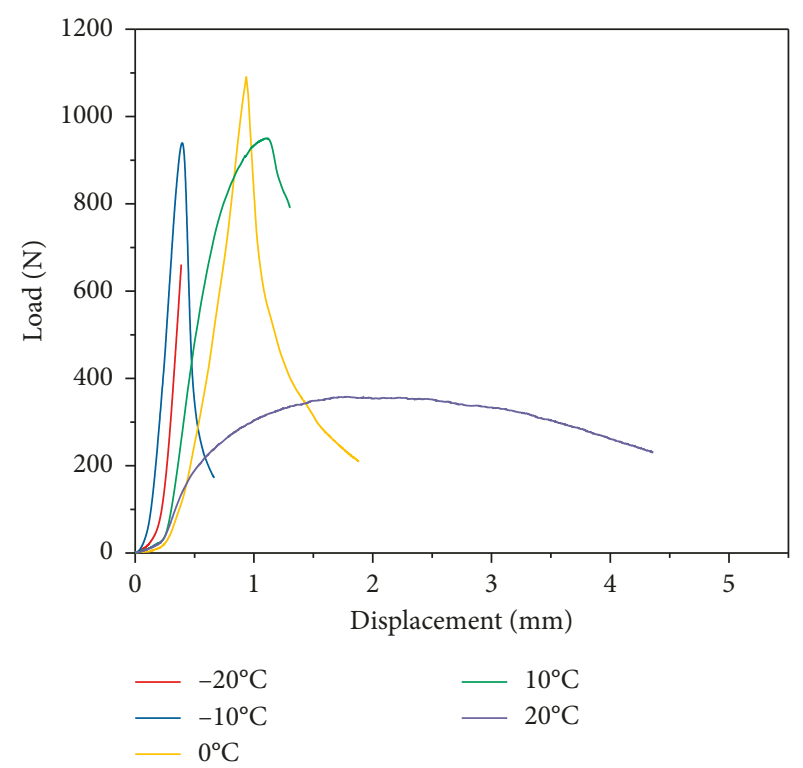

(b)

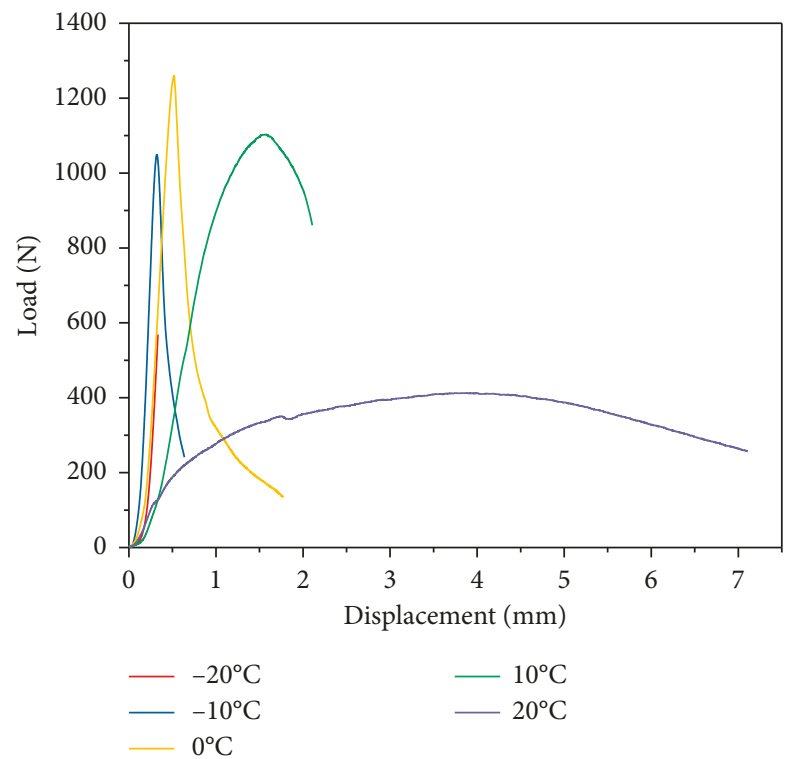

(c)

FIgURE 9: Load-displacement curves at different temperatures: (a) AC-13, (b) AC-16, and (c) SMA-13.

load-displacement curves at different temperatures. According to Figure 9, AC-13, AC-16, and SMA-13 have similar load-displacement curves at different temperatures. At $-20^{\circ} \mathrm{C}$, the loads rise rapidly, and there are no peak values until fracture failure which indicates that the SENB specimens are brittle failure in the three-point bending tests at $-20^{\circ} \mathrm{C}$. When the temperature increases (from $-10^{\circ} \mathrm{C}$ to $10^{\circ} \mathrm{C}$ ), the specimens present a certain toughness, the load of the beam increases first and then decreases with the displacement. In particular, when the temperature increases to $20^{\circ} \mathrm{C}$, it is obvious that the load-displacement curves at $20^{\circ} \mathrm{C}$ are noticeably different from the curves at the lower temperatures. At $20^{\circ} \mathrm{C}$, the linearly increase stage of the load reduces and the load rises steadily with the displacement and the load decreases when the fracture grows to a certain extent and the specimen fracture failure occurs until the displacement reaches a relatively large value compared with that at lower temperatures.

4.2.2. Loading. Figure 10 shows the ultimate loads for the SENB specimens of the three mixtures at different temperatures. The ultimate loads increase at first and then decrease and reach the maximum at $0^{\circ} \mathrm{C}$, which could be resulted in that asphalt mixture is a viscoelastic material that the mechanical properties depend with temperatures. The SENB specimens are brittle fracture at $-20^{\circ} \mathrm{C}$, and the ultimate load is small, and toughness of the SENB specimens 


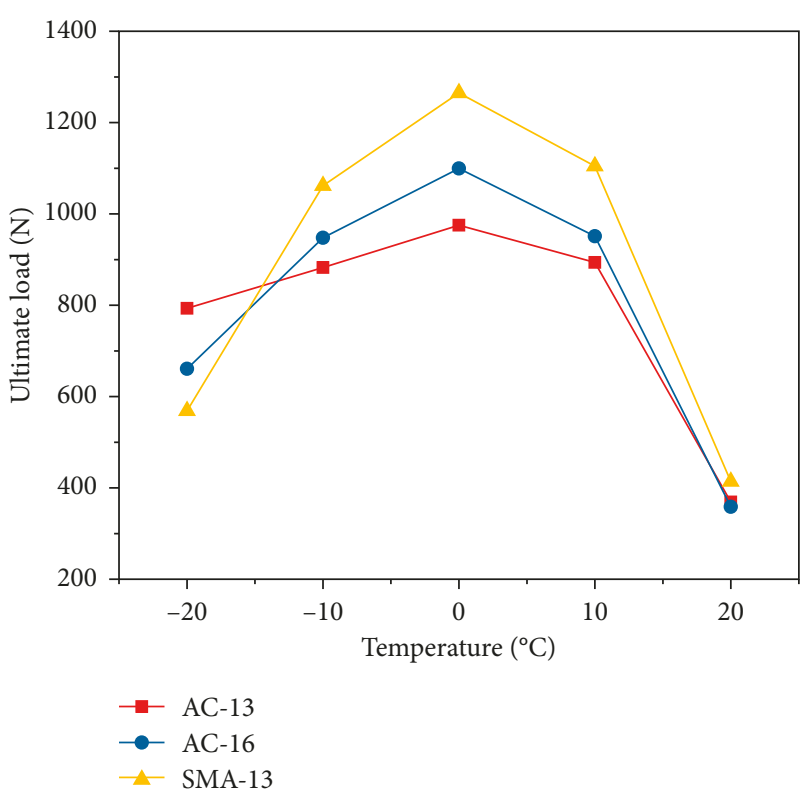

FIGURE 10: Ultimate loads at different temperatures.

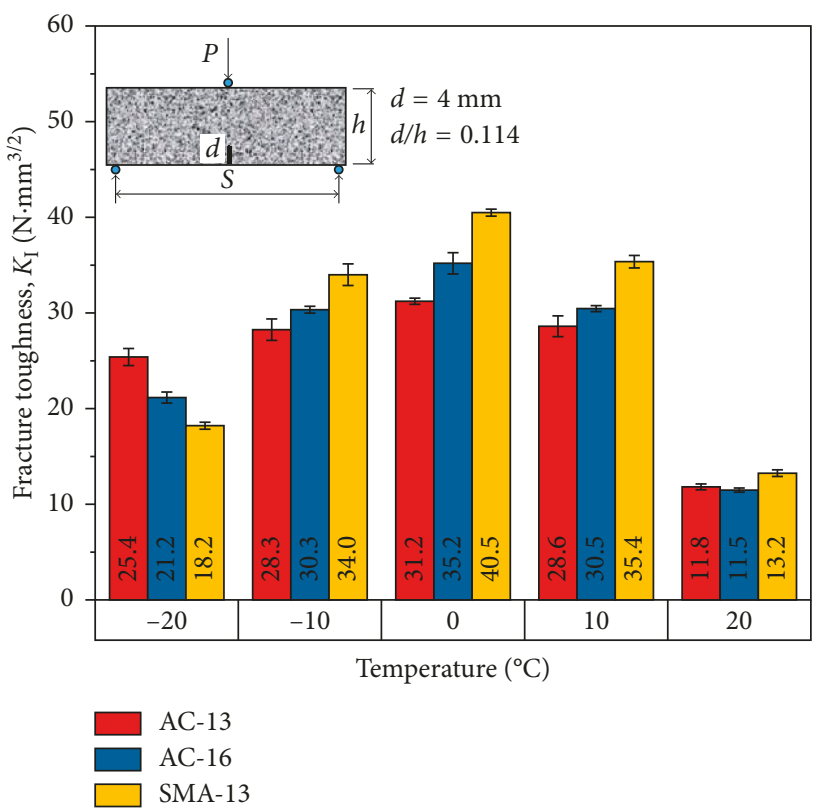

Figure 11: Fracture toughness at different temperatures.

increases with temperatures which contributes to the ultimate load increase. The tensile strength of the SENB specimens decreases with temperatures after the critical temperature, and the ultimate load decreases.

4.2.3. Fracture Toughness. Figure 11 shows the fracture toughness at different temperatures for SENB specimens using the three asphalt mixtures. It can be found that the fracture toughness at $-20^{\circ} \mathrm{C}$ of $\mathrm{AC}-13$ and $\mathrm{AC}-16$ is higher than that of SMA-13. However, it can be seen that SMA-13 has higher fracture toughness than AC-13 or AC-16 has at

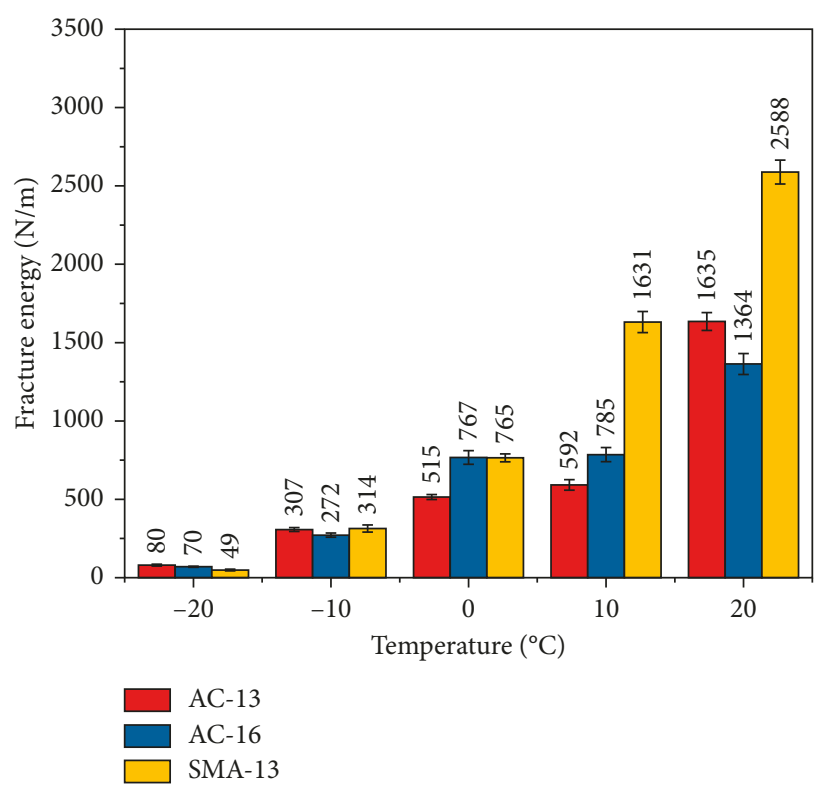

Figure 12: Fracture energy at different temperatures.

temperatures from $-10^{\circ} \mathrm{C}$ to $20^{\circ} \mathrm{C}$, indicating its better resistance to fracture generally.

4.2.4. Fracture Energy. The fracture energy at different temperatures for SENB specimens using the three asphalt mixtures is shown in Figure 12. It can be seen from Figure 12 that the fracture energy increases with temperatures. At the lower temperatures, $-20^{\circ} \mathrm{C}$ and $-10^{\circ} \mathrm{C}$, the asphalt mixtures present relatively notable elasticity and SENB specimens trend to brittle crack, consequently the three asphalt mixtures have similar fracture energy. At the higher temperatures, $0^{\circ} \mathrm{C}$ to $20^{\circ} \mathrm{C}$, the asphalt mixtures present relatively notable viscosity especially at moderate temperatures, $10^{\circ} \mathrm{C}$ to $20^{\circ} \mathrm{C}$, which the fracture energy greatly differs among the three asphalt mixtures. From Figure 12, the fracture energy of SMA-13 is significantly larger than those of AC-13 and AC- 16 .

\section{Conclusions}

This study adopted the SENB test to evaluate the fracture properties of three typical surface layer asphalt mixtures, AC-13, AC-16, and SMA-13, changing with variations of notched depths and temperatures. The following conclusions can be drawn:

(1) The notch depth has no significant effects on the fracture toughness and the fracture energy, but the gradation has relatively obvious effects on the fracture energy, which the larger contents of course aggregate results to increase the discreteness of the fracture energy of the specimen.

(2) The ultimate loads of the SENBs reach the maximum at $0^{\circ} \mathrm{C}$, which could be resulted in that viscoelastic properties of asphalt mixture depend with temperatures.

(3) The fracture toughness at $-20^{\circ} \mathrm{C}$ of continuously graded asphalt mixtures are higher than those of 
gap-graded asphalt mixtures. On the contrary, the fracture toughness of gap-graded asphalt mixtures is higher at temperatures from $-10^{\circ} \mathrm{C}$ to $20^{\circ} \mathrm{C}$.

(4) Temperature has significant effects on the fracture energy, and the fracture energy increases with temperatures. The fracture energy of SMA-13 is significantly larger than those of AC-13 and AC-16.

\section{Conflicts of Interest}

The authors declare that they have no conflicts of interest.

\section{Acknowledgments}

This research was sponsored by the Natural Science Foundation of Shaanxi Province (2016JQ5115), the PhD Research Startup Foundation of Xi'an University of Science and Technology (2017QDJ024), the opening fund of Guangxi Key Lab of Road Structure and Materials (2017gxjgclkf-001), the opening fund of Key Laboratory for Special Area Highway Engineering of Ministry of Education (300102218512), and the Outstanding Youth Science Fund of Xi'an University of Science and Technology (2018YQ3-07). The results and opinions presented are those of the authors and do not necessarily reflect those of the sponsoring agencies.

\section{References}

[1] H. Kim, M. P. Wagoner, and W. G. Buttlar, "Simulation of fracture behavior in asphalt concrete using a heterogeneous cohesive zone discrete element model," Journal of Materials in Civil Engineering, vol. 20, no. 8, pp. 552-563, 2008.

[2] Q. Dai and K. Ng, "2D cohesive zone modeling of crack development in cementitious digital samples with microstructure characterization," Construction and Building Materials, vol. 54, pp. 584-595, 2014.

[3] I. Artamendi and H. A. Khalid, "A comparison between beam and semi-circular bending fracture tests for asphalt," Road Materials and Pavement Design, vol. 7, no. s1, pp. 163-180, 2011.

[4] M. H. Sadd and Q. Dai, "A comparison of micro-mechanical modeling of asphalt materials using finite elements and doublet mechanics," Mechanics of Materials, vol. 37, no. 6, pp. 641-662, 2005.

[5] W. Buttlar and Z. You, "Discrete element modeling of asphalt concrete: Microfabric approach," Transportation Research Record: Journal of the Transportation Research Board, vol. 1757, pp. 111-118, 2001.

[6] S. J. Sulaiman and A. F. Stock, "The use of fracture mechanics for the evaluation of asphalt mixes," in Association of Asphalt Paving Technologists Technical Sessions, 1995, pp. 500-531, Portland, OR, USA, 1995.

[7] J. M. M. Molenaar and A. A. A. Molenaar, "Fracture toughness of asphalt in the semi-circular bend test," in Proceedings of the 2nd Eurasphalt \& Eurobitume Congress, pp. 509-517, Barcelona, Spain, September 2000.

[8] M. P. Wagnoner, W. G. Buttlar, and G. H. Paulino, "Diskshaped compact tension test for asphalt concrete fracture," Experimental Mechanics, vol. 45, no. 3, pp. 270-277, 2005.

[9] G. S. Xeidakis, I. S. Samaras, D. A. Zacharopoulos, and G. E. Papakaliatakis, "Crack growth in a mixed-mode loading on marble beams under three point bending," International Journal of Fracture, vol. 79, no. 2, pp. 197-208, 1996.
[10] A. Braham, W. Buttlar, and F. Ni, "Laboratory mixed-mode cracking of asphalt concrete using the single-edge notch beam," Road Materials and Pavement Design, vol. 11, no. 4, pp. 947-968, 2011.

[11] J. E. Srawley, "Wide range fracture toughness expressions for ASTM E 399 standard fracture toughness specimens," International Journal of Fracture, vol. 12, no. 3, pp. 475-476, 1976.

[12] Y. Murakami and S. Aoki, Stress Intensity Factors Handbook, vol. 2, Pergamon, Oxford, UK, 1987.

[13] J. E. Srawley and W. F. Brown Jr., Fracture Toughness Testing, National Aeronautics and Space Administration, Lewis Research Center, Cleveland, OH, USA, 1965.

[14] J. E. Srawley and B. Gross, Stress Intensity Factors for CracklineLoaded Edge-Crack Specimens, National Aeronautics and Space Administration, Washington, DC, USA, 1967.

[15] J. E. Srawley, M. H. Jones, and B. Gross, Experimental Determination of the Dependence of Crack Extension Force on Crack Length for a Single-Edge-Notch Tension Specimen, National Aeronautics and Space Administration, Washington, DC, USA, 1964.

[16] RILEM, "Determination of the fracture energy of mortar and concrete by means of three-point bend tests on notched beams," Materials and Structures, vol. 18, no. 4, pp. 285-290, 1985.

[17] P.-E. Petersson and L. Tekniska, Crack Growth and Development of Fracture Zones in Plain Concrete and Similar Materials, Lund Institute of Technology, Lund, Sweden, 1981.

[18] M. Hossain, S. Swartz, and E. Hoque, "Fracture and tensile characteristics of asphalt-rubber concrete," Journal of Materials in Civil Engineering, vol. 11, no. 4, pp. 287-294, 1999.

[19] G.-F. Peng, W.-W. Yang, J. Zhao, Y.-F. Liu, S.-H. Bian, and L.-H. Zhao, "Explosive spalling and residual mechanical properties of fiber-toughened high-performance concrete subjected to high temperatures," Cement and Concrete Research, vol. 36 , no. 4, pp. 723-727, 2006. 


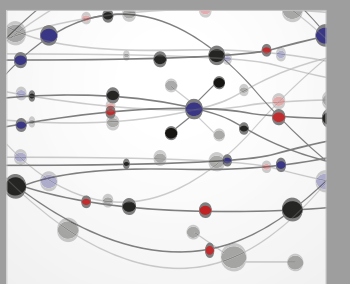

The Scientific World Journal
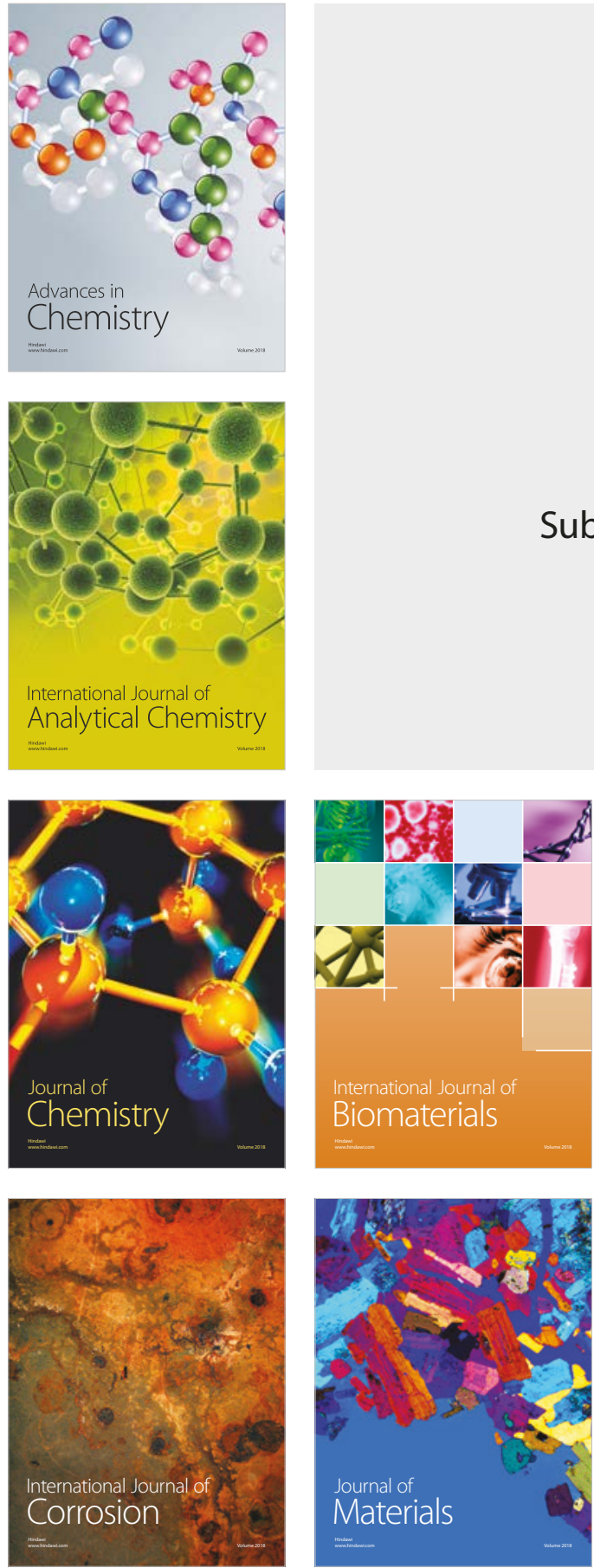

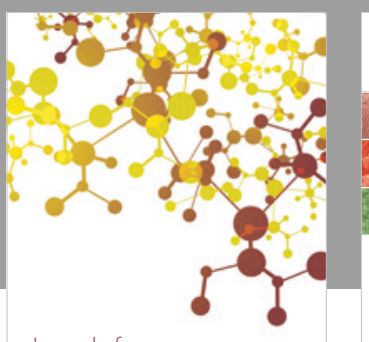

Journal of

Applied Chemistry
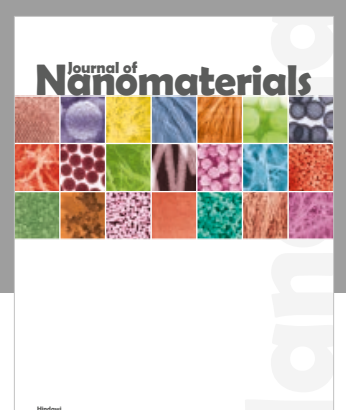

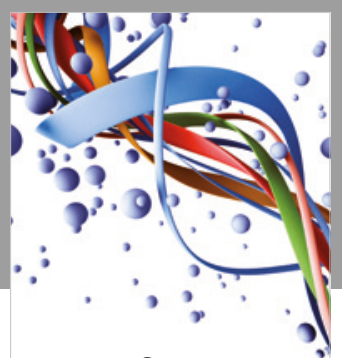

Scientifica

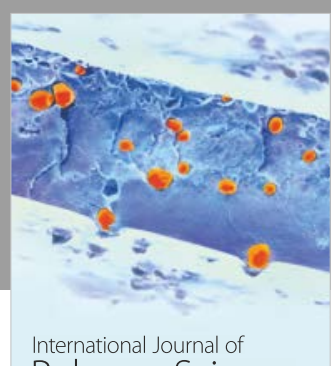

Polymer Science

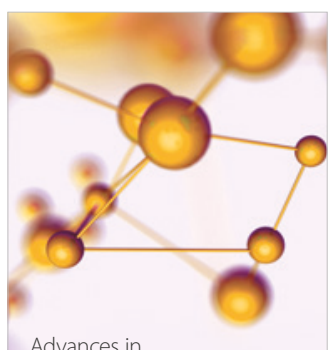

Physical Chemistry
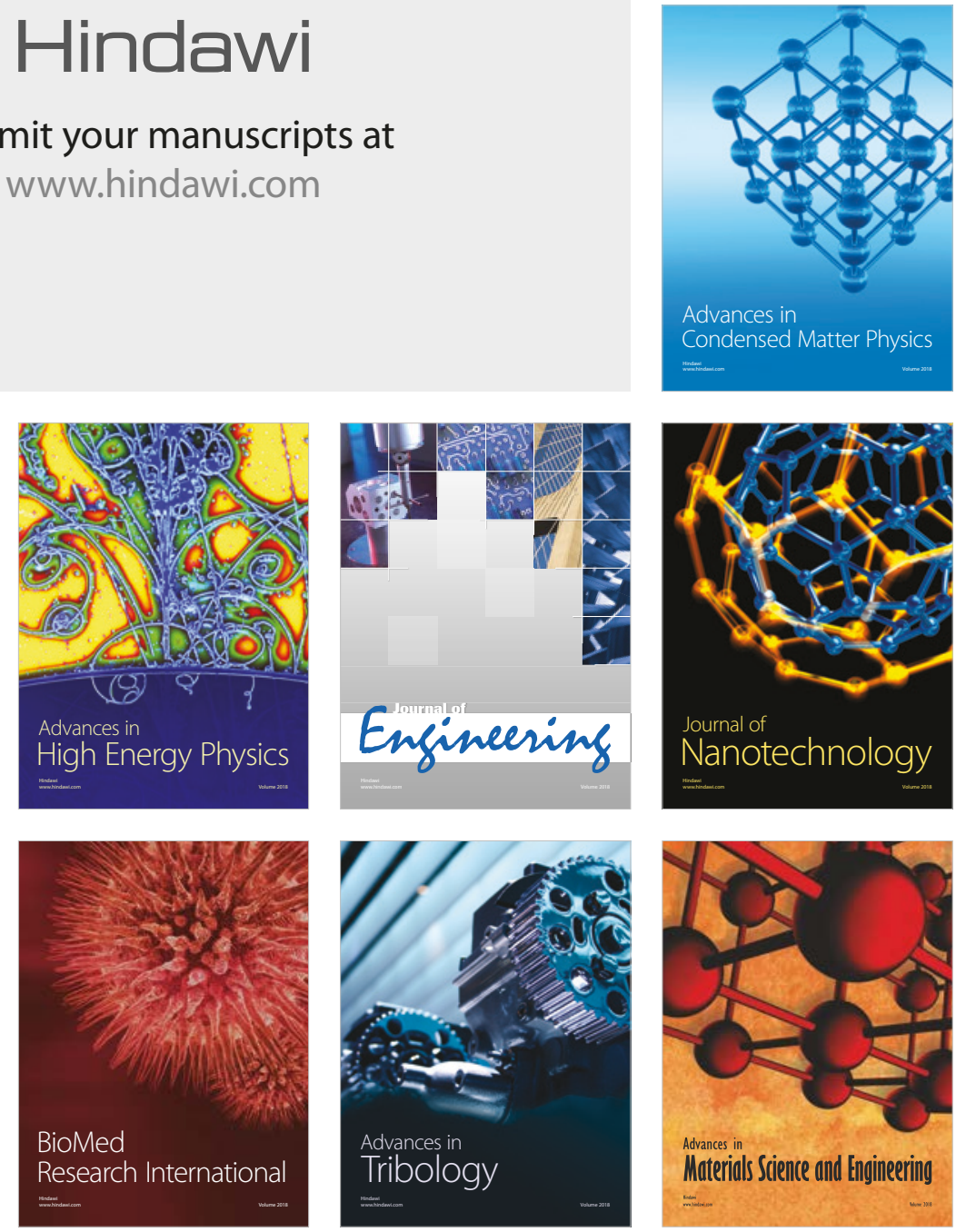